\title{
Estudo das propriedades reológicas, mecânicas e de blindagem eletromagnética de misturas elastoméricas envolvendo borracha nitrílica (NBR) e borracha nitrílica carboxilada (XNBR)
}

\section{Study of rheological, mechanical and electromagnetic shielding properties of Nitrile rubber (NBR) and Carboxylated Nitrile rubber (XNBR) blends}

\author{
Loan Filipi Calheiros Soutoㄹ, Matheus Magioli Cossa², Bluma Guenther Soares² e Alex da Silva Siqueira1* \\ ${ }^{1}$ Centro Universitário Estadual da Zona Oeste - UEZO, Rio de Janeiro, RJ, Brasil \\ ${ }^{2}$ Instituto de Macromoléculas Professora Eloisa Mano - IMA, Universidade Federal do Rio de Janeiro - \\ UFRJ, Rio de Janeiro, RJ, Brasil \\ *alexsirqueira@uezo.rj.gov.br
}

\begin{abstract}
Resumo
Neste trabalho foram avaliadas as propriedades reológicas, mecânicas e de blindagem eletromagnética de misturas elastoméricas envolvendo borracha nitrílica (NBR) e borracha nitrílica carboxilada (XNBR) formuladas com 30 pcr de negro de fumo condutor. As proporções de NBR/XNBR estudadas foram 100/0, 80/20, 50/50, 20/80, 10/90 e 0/100. Os resultados obtidos demonstraram que o aumento no teor de XNBR reduziu a taxa de vulcanização (CRI), contudo as propriedades mecânicas aumentaram em relação às amostras com alto teor de NBR. Através da análise de microscopia eletrônica de varredura foi observada uma melhor dispersão do negro de fumo condutor nas composições ricas em XNBR, que também apresentaram maior resistência ao inchamento. Estes resultados corroboram com os valores encontrados para a resistência à tração. A maior atenuação na faixa do radar foi observada também para a amostra contendo somente a borracha nitrílica carboxilada, o valor de atenuação encontrado foi de $50 \%$ da energia emitida, aproximadamente $-3 \mathrm{~dB}$.
\end{abstract}

Palavras-chave: borracha nitrílica, blindagem eletromagnética, XNBR, vulcanização.

\begin{abstract}
This work evaluated the rheological, mechanical and electromagnetic shielding properties of nitrile rubber (NBR) and carboxylated nitrile rubber (XNBR) blends added with $30 \mathrm{phr}$ of conductive carbon black. The NBR/XNBR ratios studied were $100 / 0,80 / 20,50 / 50,20 / 80,10 / 90$ e $0 / 100$. The results obtained showed that increasing the content of XNBR in the blends, reduced the vulcanization rate (CRI), but the mechanical properties have increased in relation to the samples with high NBR content. Through the analysis of scanning electron microscopy showed that the carbon black were dispersed best in compositions rich on XNBR elastomer, these samples also showed higher resistance to swelling. Result that corroborates with the values found for tensile strength. The greater attenuation on radar range was also observed to the sample containing only nitrile rubber, the attenuation value was $50 \%$ of the absorbed energy, approximately $-3 \mathrm{~dB}$.
\end{abstract}

Keywords: nitirle rubber, shielding electromagnetic, XNBR, vulcanization.

\section{Introdução}

Os materiais elastoméricos raramente são utilizados sem a presença de aditivos químicos, tais como: cargas reforçantes; plastificantes; antioxidantes; agentes de cura; agentes antiestáticos e outros. Esses aditivos têm o objetivo de melhorar o desempenho mecânico do artefato vulcanizado, aumentar a resistência ao envelhecimento, reduzir o preço e o peso específico. Geralmente, os aditivos químicos utilizados são tóxicos e de fontes não renováveis, causadores de grande impacto ambiental quando descartados de maneira inconveniente. Atualmente, existe uma intensa busca por aditivos menos poluentes capazes de substituírem os aditivos químicos convencionais ${ }^{[1]}$.

Alguns elastômeros apresentam em sua estrutura molecular grupos químicos capazes de reagirem entre si ou com outros 
polímeros, possibilitando a compatibilização reativa entre pares dissimilares, reduzindo o teor dos aditivos químicos utilizados nas formulações. Um elastômero que apresenta essa característica é a borracha nitrílica carboxilada (XNBR). Os grupos carboxílicos presentes na estrutura molecular da borracha nitrílica permitem a reação com outras moléculas ou superfícies funcionalizadas de cargas ${ }^{[2]}$. Servem também como um ponto adicional para formação de ligações cruzadas iônicas ${ }^{[3,4]}$, na presença de óxidos metálicos. A formação de ligações cruzadas iônicas entre o grupo carboxílico e o óxido metálico gera o ionômero, que contribuirá para o aumento do módulo e da resistência à tração do material $\operatorname{vulcanizado}^{[5]}$.

O negro de fumo é o aditivo químico mais utilizado pela indústria de elastômeros, pois é capaz de conferir reforço mecânico ao material ou torná-lo condutor de eletricidade. O negro de fumo condutor é um aditivo não reforçante, que possibilita a obtenção de um material elastomérico extrinsecamente condutor de eletricidade (a condução elétrica não ocorre pelo elastômero e sim pela carga condutora $)^{[6]}$. O material extrinsecamente condutor pode atuar também como absorvedor de radiação eletromagnética ${ }^{[7-12]}$.

De maneira simplificada, pode-se dizer que os materiais absorvedores de radiação (Radar Absorbing Materials) promovem a troca de energia da radiação eletromagnética pela energia térmica, devido às características intrínsecas de determinados componentes, como os materiais carbonosos, polímeros condutores e ferritas ${ }^{[8]}$. Esses materiais, quando atingidos por uma onda eletromagnética, têm a sua estrutura molecular excitada e a energia incidente é convertida em calor. Alguns desses materiais têm a capacidade de absorverem na faixa do radar $(8 \mathrm{a} 12 \mathrm{GHz})$, tornando-os invisíveis ou proporcionando uma eficiente blindagem eletromagnética ${ }^{[9]}$. Essas características ganharam importância nos setores militar e aeroespacial. Outras aplicações têm sido realizadas em outras áreas, como na fabricação de televisores, computadores, telefones celulares, salas de instrumentação, antenas de rádio-transmissão, equipamentos de comunicação, entre outros

Na literatura, encontra-se amplo material sobre a utilização de materiais absorvedores de radiação eletromagnética. Recentemente, foi publicada uma revisão que aborda o estado da arte da blindagem eletromagnética, e a correlação da eficiência de blindagem com a boa dispersão da carga condutora na matriz polimérica ${ }^{[12]}$.

Neste trabalho, buscou-se avaliar as propriedades reológicas, mecânicas e de blindagem eletromagnética de misturas envolvendo borracha nitrílica e borracha nitrílica carboxilada, aditivadas com negro de fumo condutor. Visa-se a obter um material de revestimento capaz de atenuar a radiação eletromagnética na faixa do radar.

\section{Experimental}

\subsection{Materiais}

As borrachas utilizadas neste estudo foram a borracha nitrílica, NBR N-608 (teor de acrilonitrila $=33 \%$, viscosidade Mooney $=80$ e polimerização a frio) e a borracha nitrílica carboxilada, XNBR 3350X, (teor de acrilonitrila $=26-28 \%$, viscosidade Mooney $=48$, teor de carboxila $=7 \%$ e polimerização a frio), ambas fornecidas gentilmente pela empresa Nitriflex Indústria e Comércio. O negro de fumo condutor utilizado foi o XC72 (área superficial $=180 \mathrm{~m}^{2} / \mathrm{g}$, Diâmetro de partículas $=29 \mathrm{~nm})$, fornecida pela empresa Cabot. O sistema de vulcanização utilizado foi composto por Óxido de Zinco, Ácido Esteárico, TMTD e Enxofre, todos fornecidos de empresas locais. O Clorofórmio foi fornecido pela Vetec.

\subsection{Preparo das misturas e medidas reométricas}

As misturas de NBR/XNBR foram preparadas em um misturador de cilindros a $50^{\circ} \mathrm{C}$ com velocidade de rotação de 20 e 22 RPM. As composições foram formuladas para $100 \mathrm{pcr}$ (parte por cem partes de borracha) de mistura elastomérica. Inicialmente foram processadas as borrachas NBR e XNBR por $3 \mathrm{~min}$. e em seguida, foi adicionado $30 \mathrm{pcr}$ de negro de fumo, com tempo de homogeneização de $2 \mathrm{~min}$. Após este período de processamento, foram adicionados os agentes de vulcanização da mistura, obedecendo a seguinte ordem: óxido de zinco (5 pcr), ácido esteárico (1 pcr), enxofre $(0,8$ pcr $)$ e TMTD ( 1 pcr $)$. O tempo de processamento após a adição de cada componente foi de cerca de $2 \mathrm{~min}$., totalizando 15 minutos. Foram obtidas seis formulações envolvendo o par elastomérico NBR/XNBR, 100/0, 80/20, $50 / 50,20 / 80,10 / 90$ e 0/100, o intuito foi verificar o efeito da carboxila na dispersão do negro de fumo. Os parâmetros de vulcanização das misturas foram determinados a partir dos dados do reômetro de disco oscilatório, ODR, que operou nas seguintes condições de análise: arco de oscilação de $1^{\circ}$, tempo de vulcanização de 24 minutos, temperatura de $170{ }^{\circ} \mathrm{C}$, de acordo com a norma ASTM D-2084-11. A taxa de vulcanização (CRI) foi calculada através da Equação 1.

$$
C R I=100 /\left(t_{90}-t_{s 1}\right)
$$

Onde: $\mathrm{t}_{90}$ é o tempo ótimo de cura e $\mathrm{t}_{\mathrm{s} 1}$ é o tempo de segurança.

\subsection{Ensaios mecânicos e inchamento}

Os parâmetros de vulcanização obtidos através do ODR foram utilizados para a moldagem por compressão das misturas em prensas hidráulicas à temperatura de $170^{\circ} \mathrm{C}$. Os corpos de prova para o ensaio de resistência à tração foram obtidos de acordo com a norma DIN 53504. O ensaio de tração foi realizado em uma maquina universal de ensaios EMIC, com velocidade de separação das garras de $200 \mathrm{~mm} / \mathrm{min}$.

A resistência ao inchamento em solvente orgânico foi realizada para avaliar o grau de reticulação das misturas. A metodologia consistiu em preparar os corpos de prova no formato retangular, pesar e imergi-los em clorofórmio até atingir peso constante (equilíbrio), obtido após 48 horas de imersão.

As misturas vulcanizadas foram submetidas ao ensaio de envelhecimento em estufa com circulação forçada de ar, na temperatura de $100{ }^{\circ} \mathrm{C}$ em diferentes intervalos de tempo $24 \mathrm{~h}, 48 \mathrm{~h}$ e $72 \mathrm{~h}$. As amostras após o ensaio de envelhecimento foram submetidas ao inchamento em clorofórmio para determinar o efeito de degradação das misturas vulcanizadas.

\subsection{Medidas de absortividade}

As misturas foram caracterizadas por atenuação de radiação eletromagnética. Esta análise permite quantificar os fenômenos de interação da radiação eletromagnética com o material atenuador. As medidas de refletividade das formulações 
foram realizadas, utilizando-se um guia de ondas acoplado a um gerador de sinais, Agilent $83752^{\mathrm{a}}$ (Synthesized Sweeper), configurado para a faixa de frequência de 8,0 a $12,0 \mathrm{GHz}$.

A eficiência de blindagem (EB) foi calculada através da razão entre a potência da radiação incidente $(\mathrm{Pi})$, e a potência da radiação transmitida $(\mathrm{Pt})$, Equação $2^{[9]}$.

$$
E B=10 \times \log \left(P_{i} / P_{t}\right)
$$

\subsection{Caracterização morfológica}

A morfologia das misturas de NBR/XNBR foi avaliada através de microscópio eletrônico de varredura (MEV), marca Jeol. As amostras foram recobertas com ouro e utilizou-se o feixe de elétrons retroespalhados com potência de $15 \mathrm{kv}$.

\section{Resultados e Discussão}

Uma das principais caracterizações empregadas na tecnologia de elastômeros é a caracterização reométrica durante o processo de vulcanização. Através dos dados obtidos pelo reômetro, avalia-se efetivamente o efeito do sistema de cura (ou vulcanização) utilizado na formulação do composto e sua influência na vulcanização. Os principais parâmetros obtidos por essa técnica são: torque máximo, torque mínimo, tempo ótimo de cura e taxa de vulcanização.

A Tabela 1 apresenta os resultados das propriedades reométricas das misturas NBR/XNBR com negro de fumo condutor. Para este estudo, optou-se por utilizar um sistema de vulcanização classificado como semi-eficiente, no qual a quantidade de enxofre utilizada é aproximadamente igual à quantidade de acelerador. Embora, para elastômeros polares, como a borracha nitrílica, a literatura recomende preferencialmente o sistema eficiente (acelerador em maior quantidade), essa recomendação ocorre em função da baixa solubilidade do enxofre na $\mathrm{NBR}^{[1,3]}$.

O torque mínimo está relacionado com a viscosidade do material. Nota-se que o aumento no teor de borracha nitrílica carboxilada reduz o torque mínimo. Esse comportamento pode ser atribuído à baixa viscosidade Mooney da XNBR em relação à borracha nitrílica. A diferença entre o torque máximo e o torque mínimo está relacionada com a densidade de ligações cruzadas. Nota-se que a adição de XNBR provoca aumento no valor da diferença de torques. Esse resultado indica que a presença da XNBR aumenta a densidade de ligação cruzada das misturas, comportamento que pode ser atribuído à presença de dois sítios de cura na XNBR, um originado pela formação das ligações sulfídicas e outro, pela formação de ligações iônicas com o óxido de zinco e o grupo carboxila da XNBR. A taxa de vulcanização (CRI) sofre redução de 67\% com o aumento da XNBR, ou seja, o aumento no teor de borracha nitrílica carboxilada na mistura reduz a taxa de formação de ligações cruzadas. Mas esse resultado não implica em redução do teor de ligações cruzadas formadas, observado pelo aumento do torque máximo. Estudos sobre o processo de vulcanização da borracha nitrílica carboxilada mostram que o processo ocorre em duas etapas (ligações iônicas e covalentes) ${ }^{[4,13]}$. A queda no CRI pode estar associada à competição pelo óxido de zinco na formação do ionômero (ligação iônica) e na ativação do complexo sulfurante, responsável pela formação das ligações sulfídicas ${ }^{[13-15]}$.

Através dos resultados das propriedades mecânicas de resistência à tração e módulo, observa-se que o aumento do teor de XNBR aumenta o valor da tração na ruptura e o módulo das amostras vulcanizadas. Esse comportamento corrobora com os resultados obtidos pelo reômetro de disco oscilatório para o torque máximo das misturas. A redução na taxa de formação de ligações cruzadas (CRI) não provocou redução na quantidade, apenas na velocidade de formação das redes tridimensionais.

O ensaio de inchamento em solvente foi utilizado com o intuito de avaliar o sistema de vulcanização empregado e a densidade de ligações cruzadas formadas. Quanto maior for a quantidade de ligações cruzadas, menor será o percentual de borracha inchada. Desta maneira, avalia-se indiretamente a eficiência do sistema de vulcanização, na formação de ligações covalentes. A Figura 1 apresenta os resultados do

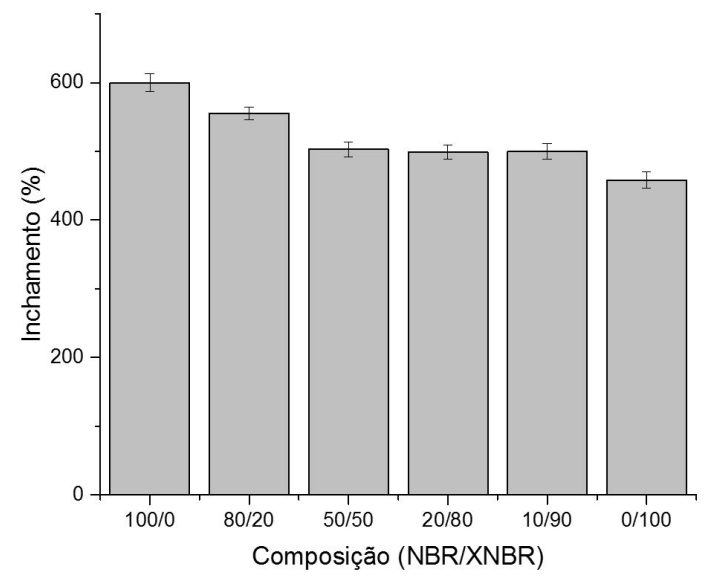

Figura 1. Variação do percentual de material vulcanizado inchado em clorofórmio das misturas NBR/XNBR.

Tabela 1. Parâmetros de vulcanização das misturas NBR/XNBR.

\begin{tabular}{|c|c|c|c|c|c|c|c|c|}
\hline $\begin{array}{c}\text { Misturas } \\
\text { NBR/XNBR }\end{array}$ & $\begin{array}{c}M_{L} \\
\text { (dN.m) }\end{array}$ & $\begin{array}{c}M_{H} \\
\text { (dN.m) }\end{array}$ & $\begin{array}{l}M_{H}-M_{L} \\
\text { (dN.m) }\end{array}$ & $\begin{array}{c}\mathbf{t}_{\mathrm{s1}} \\
(\mathrm{min})\end{array}$ & $\begin{array}{c}t_{90} \\
(\mathrm{~min})\end{array}$ & $\begin{array}{c}\text { CRI } \\
(\mathrm{min})^{-1}\end{array}$ & $\begin{array}{c}\text { Módulo a } \\
100 \% \text { de } \\
\text { deformação } \\
\text { (MPa) }\end{array}$ & $\begin{array}{c}\text { Tração na } \\
\text { ruptura } \\
\text { (MPa) }\end{array}$ \\
\hline $100 / 0$ & 7,0 & 29,2 & 22,2 & 1,38 & 3,01 & 61,34 & 4,62 & 13,97 \\
\hline $80 / 20$ & 7,4 & 34,4 & 27,0 & 1,32 & 3,27 & 51,28 & 5,23 & 18,86 \\
\hline $50 / 50$ & 6,7 & 37,7 & 31,0 & 1,48 & 4,17 & 37,17 & 6,62 & 22,70 \\
\hline $20 / 80$ & 5,6 & 38,6 & 33,0 & 1,08 & 5,07 & 25,06 & 8,06 & 23,39 \\
\hline $10 / 90$ & 4,6 & 36,8 & 32,2 & 1,50 & 5,51 & 24,93 & 8,08 & 25,04 \\
\hline $0 / 100$ & 4,2 & 36,7 & 32,5 & 1,41 & 6,58 & 19,34 & 8,61 & 26,80 \\
\hline
\end{tabular}

$\mathrm{M}_{\mathrm{L}}=$ torque Máximo; $\mathrm{M}_{\mathrm{H}}=$ torque mínimo; $\mathrm{t}_{\mathrm{s}}=$ tempo de segurança; $\mathrm{t}_{90}=$ tempo ótimo de cura. 
inchamento em clorofórmio das misturas não submetidas ao envelhecimento acelerado em estufa com circulação de ar. Compostos vulcanizados à base de borracha nitrílica são amplamente utilizados para materiais com alta resistência a óleos e solventes. A resistência a óleos e solventes está relacionada com a polaridade da borracha. Assim, com a adição do grupo carboxila na NBR, aumenta-se essa propriedade. Nota-se, pelos resultados obtidos, que a borracha nitrílica carboxilada apresenta valores de inchamento inferiores aos da borracha nitrílica com $33 \%$ de acrilonitrila, indicando maior resistência à penetração do solvente.

Para avaliar a resistência à degradação das ligações cruzadas formadas durante a vulcanização, as amostras foram submetidas ao envelhecimento acelerado em estufa de circulação forçada de ar. Se houver aumento no valor de inchamento, isso é o indicativo de que ocorreram degradações nas ligações cruzadas da amostra, pois a difusão do solvente na matriz elastomérica é facilitada. $\mathrm{Na}$ Tabela 2, encontram-se os resultados de inchamento após o ensaio de envelhecimento em diferentes intervalos de tempo. Percebe-se que todas as misturas envelhecidas após 72 horas apresentaram redução no valor do inchamento em relação às misturas não envelhecidas. Esse comportamento pode estar associado ao efeito da pós-cura das misturas.

A morfologia das misturas vulcanizadas foi estudada pela técnica de Microscopia Eletrônica de Varredura, a fim de verificar a dispersão do negro de fumo condutor na matriz elastomérica. O negro de fumo foi caracterizado pelos pontos claros nas micrografias. Não foram verificadas grandes alterações na morfologia das misturas com o aumento da XNBR. Nota-se, através da Figura 2, que a composição com XNBR apresentou maior dispersão da carga condutora.

Tabela 2. Variação percentual do material inchado em clorofórmio após o ensaio de envelhecimento em estufa com circulação forçada de ar

\begin{tabular}{ccccc}
\hline $\begin{array}{c}\text { Composição } \\
\text { (NBR/XNBR) }\end{array}$ & Antes do envelhecimento & $\begin{array}{c}\text { Envelhecimento } \\
\mathbf{( 2 4 h )}\end{array}$ & $\begin{array}{c}\text { Envelhecimento } \\
\mathbf{( 4 8 h )}\end{array}$ & $\begin{array}{c}\text { Envelhecimento } \\
\mathbf{( 7 2 h})\end{array}$ \\
\hline $100 / 0$ & $600 \pm 13$ & $468 \pm 12$ & $509 \pm 11$ & $509 \pm 12$ \\
$80 / 20$ & $555 \pm 9$ & $520 \pm 20$ & $355 \pm 10$ & $420 \pm 12$ \\
$50 / 50$ & $503 \pm 11$ & $500 \pm 11$ & $470 \pm 9$ & $434 \pm 9$ \\
$20 / 80$ & $499 \pm 10$ & $427 \pm 9$ & $446 \pm 13$ & $391 \pm 11$ \\
$10 / 90$ & $500 \pm 11$ & $422 \pm 7$ & $459 \pm 12$ & $426 \pm 11$ \\
$0 / 100$ & $458 \pm 12$ & $396 \pm 15$ & $410 \pm 13$ & $429 \pm 10$ \\
\hline
\end{tabular}

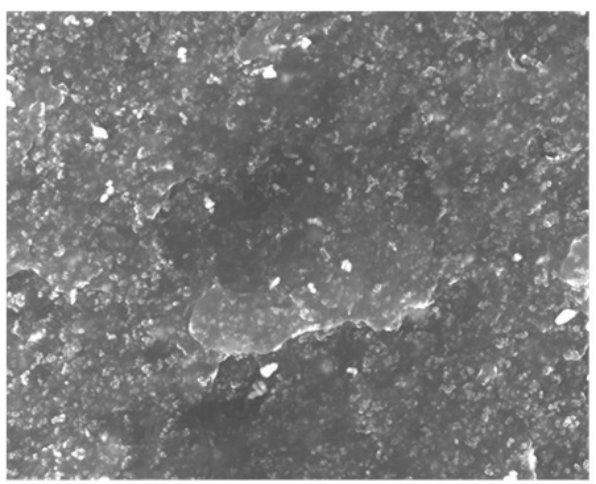

Mistura $100 / 0$

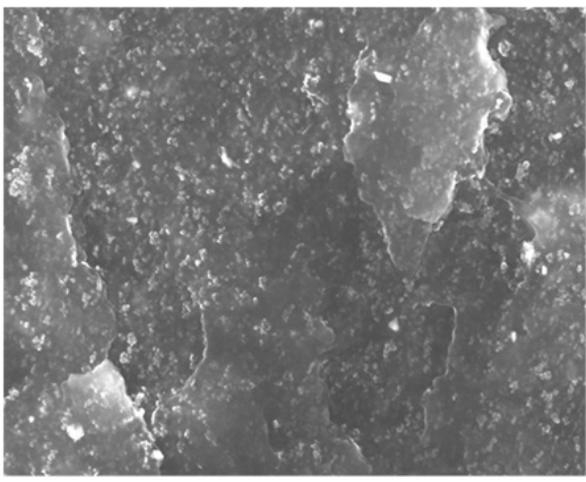

Mistura 50/50

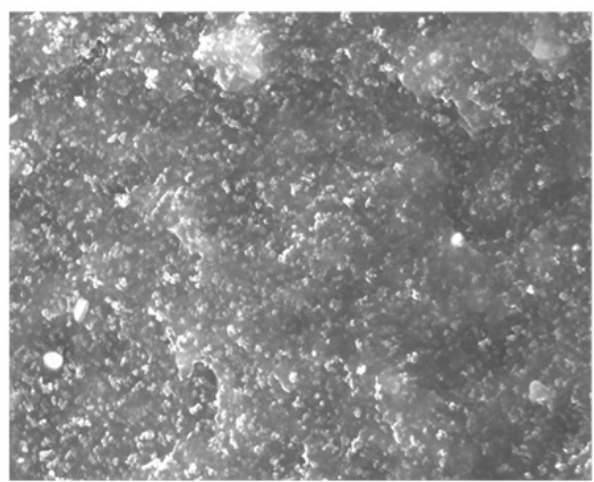

Mistura $0 / 100$

Figura 2. Micrografia das misturas NBR/XNBR vulcanizadas. 
Assim, especula-se que a redução da viscosidade favoreça a dispersão da carga condutora na mistura. Espera-se que as misturas contendo altos teores de XNBR apresentem maior efeito de blindagem eletromagnética, devido à melhor dispersão do negro de fumo.

As medidas de refletividade da radiação eletromagnética, na faixa de 8 a $12 \mathrm{GHz}$, foram realizadas para as misturas de NBR/XNBR contendo 30 pcr de negro de fumo. As absortividades das misturas foram medidas para verificar a eficiência da blindagem eletromagnética, que corresponde à soma dos fenômenos de reflexão $(\mathrm{R})$, absorção (A) e múltipla-reflexão (MR). Porém, o valor de MR pode ser desprezado devido à pequena quantidade de sinal atenuada por este fenômeno. A relação entre a reflexão e absorção, expressa pela Equação 3, representa a quantidade de radiação eletromagnética que é atenuada por um material ${ }^{[10]}$.

$$
S E=R+A
$$

Os resultados obtidos através do guia de ondas podem ser vistos na Tabela 3.
Observa-se, através dos valores da Tabela 3 e da Figura 3, que não houve diferença significativa nos valores de absortividade das misturas. No entanto, a composição com 100 pcr de XNBR apresentou valores próximos a $-3 \mathrm{~dB}$, o equivalente a $50 \%$ da energia absorvida ${ }^{[11]}$. A maior atenuação da radiação observada para esta composição pode estar relacionada à presença de cargas condutoras mais dispersas, como verificado nas análises de MEV. Essas podem atuar como centros absorvedores de radiação mais eficientes, promovendo a perda ôhmica da radiação incidente ${ }^{[8]}$.

Tabela 3. Resultados obtidos da absortividade das composições NBR/XNBR.

\begin{tabular}{cccc}
\hline NBR/XNBR & F(Hz) & RL & SE \\
\hline $100 / 0$ & 12,1E9 & $-6,59969$ & $-2,17733$ \\
$80 / 20$ & $8,41 \mathrm{E} 9$ & $-6,15249$ & $-2,22194$ \\
$50 / 50$ & $8,58 \mathrm{E} 9$ & $-6,32236$ & $-2,00325$ \\
$20 / 80$ & $8,24 \mathrm{E} 9$ & $-5,83233$ & $-2,25433$ \\
$10 / 90$ & $10,8 \mathrm{E} 9$ & $-5,93614$ & $-2,20475$ \\
$0 / 100$ & $8,26 \mathrm{E} 9$ & $-5,10883$ & $-2,40723$ \\
\hline
\end{tabular}

$\mathrm{F}(\mathrm{Hz})=$ faixa onde ocorre a maior atenuação; $\mathrm{RL}=$ Reflexão; $\mathrm{SE}=$ Eficiência de blindagem.

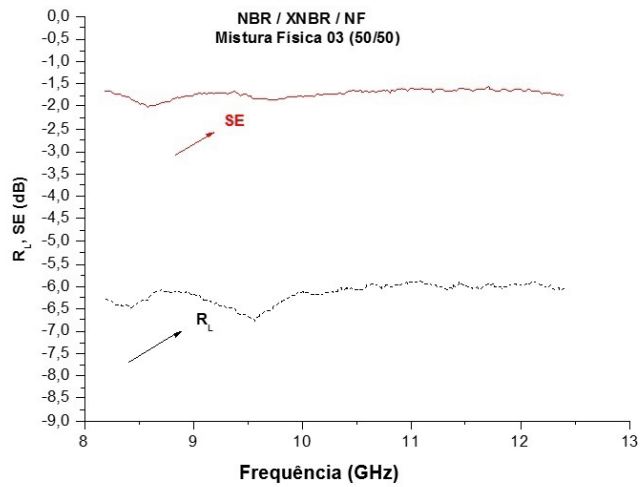

(a)

(b)

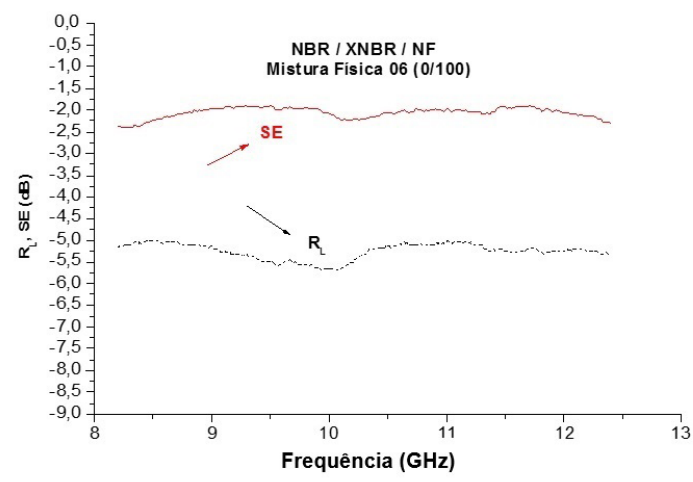

(c)

Figura 3. Gráfico de Reflexão e Eficiência de blindagem das misturas NBR/XNBR (a) 100/0; (b) 50/50; e (c) 0/100. 


\section{Conclusões}

Através dos resultados encontrados neste estudo, concluise que o teor de carboxila da XNBR afeta diretamente as propriedades de blindagem das misturas NBR/XNBR, devido à melhor dispersão do negro de fumo condutor.

$\mathrm{O}$ aumento do teor de XNBR apresenta redução da velocidade de vulcanização e maior resistência à tração.

As propriedades mecânicas das misturas sofreram acréscimo em seus valores com o aumento do teor de XNBR.

A dispersão do negro de fumo condutor na mistura NBR/XNBR foi facilitada pela redução na viscosidade da mistura, o que resultou em maior eficiência de blindagem.

\section{Agradecimentos}

Os autores agradecem à FAPERJ e ao $\mathrm{CNPq}$, pelo apoio financeiro.

\section{Referências}

1. Sirqueira, A. S., Reis, R., Sirelli, L., Silva, M. V. O., \& Monteiro, R. V. (2009). Nitrigreen a borracha ecológica. Polímeros: Ciência e Tecnologia, 19(1), 10-13. http://dx.doi.org/10.1590/ S0104-14282009000100007.

2. Bandyopadhyay, B., De, P. P., Tripathy, D. K., \& De, K. D. (1996). Influence of surface oxidation of carbon black on its interaction with nitrile rubbers. Polymer, 37(2), 353-357. http://dx.doi.org/10.1016/0032-3861(96)81110-4.

3. Celestino, M. L., \& Soares, B. G. (2013). Compatibilization efficiency of carboxylated nitrile rubber and epoxy prepolymer in nitrile/acrylic rubber blends. Polimeros: Ciência e Tecnologia, 23, 139-143. http://dx.doi.org/10.1590/S010414282013005000024

4. Merieles, D., Sirqueira, A. S., \& Soares, B. G. (2008). A novel thermoplastic elastomer based on dynamically vulcanized polypropylene/acrylic rubber blends. Express Polymer Letters, 9, 602-613. http://dx.doi.org/10.3144/expresspolymlett.2008.72.

5. Ibarra, L., Fernandes, A. M., \& Alzorriz, M. (2002). Mechanistic approach to curing of carboxylated nitrile rubber (XNBR) by zinc peroxide/zinc oxide. Polymer, 43(5), 1649-1655. http:// dx.doi.org/10.1016/S0032-3861(01)00734-0.

6. Yi, W., Wang, Y., Wang, G., \& Tao, X. (2012). Investigation of Carbon Black/Silicone elastomer/dimethysilicone oil composite for flexible strain sensor. Polymer Testing, 31(5), 677-686. http://dx.doi.org/10.1016/j.polymertesting.2012.03.006.
7. Soares, B. G., Amorim, G. S., Oliveira, M. G., \& Silva, J. P. (2006). Conducting elastomer blends based on nitrile rubber and Pani.DBSA. Macromolecular Symposia, 233(1), 95-101. http://dx.doi.org/10.1002/masy.200690033.

8. Silva, V. A., Pereira, J. J., \& Nohara, E. L. (2009). Electromagnetic behavior of radar absorbing materials based on cahexaferrite modified with cCo-Ti ions and doped with La. Journal of Aerospace Technology and Management, 1(2), 255-263. http:// dx.doi.org/10.5028/jatm.2009.0102255263.

9. Faez, C., Rezende, M. C., Martin, I. M., \& DePaoli, M. A. (2000). Polímeros condutores intrínsecos e seu potencial em blindagem de radiações eletromagnéticas. Polímeros: Ciência e Tecnologia, 10, 130-137. http://dx.doi.org/10.1590/S010414282000000300009 .

10. Das, A., Hayvaci, H. T., Tiwari, M. K., Bayer, I. S., Erricolo, D., \& Megaridis, C. M. (2011). Superhydrophobic and conductive carbon nanofiber/PTFE composite coatings for EMI shielding. Journal of Colloid and Interface Science, 353(1), 311-315. PMid:20889160. http://dx.doi.org/10.1016/j.jcis.2010.09.017.

11. Lakshmi, K., John, H., Joseph, R., George, K. E., \& Mathew, K. T. (2008). Comparison of microwave and electrical properties of selected conducting polymers. Microwave and Optical Technology Letters, 50(2), 504-508. http://dx.doi.org/10.1002/ mop.23091.

12. Thomassin, J. M., Jérôme, C., Pardoen, T., Bailly, C., Huynen, I., \& Detrembleur, C. (2013). Polymer/carbon based composite as electromagnetic interference (EMI) shielding materials. Materials Science and Engineering R Reports, 74(7), 211-232. http://dx.doi.org/10.1016/j.mser.2013.06.001.

13. Sirqueira, A. S., Carvalho, A. P. A., \& Cossa, M. M. (2014). Cinética de reticulação de borracha nitrílica carboxilada. Acta Scientiae et Thecnicae, 2(2), 13-17.

14. Kim, B. R., Lee, H. K., Kim, E., \& Lee, S. H. (2010). Intrinsic electromagnetic radiation shielding/absorbing characteristic of polyaniline-coated transparent thin films. Synthetic Metals, 160(17), 1838-1842. http://dx.doi.org/10.1016/j. synthmet.2010.06.027.

15. Sirqueira, A. S., \& Soares, B. G. (2006). O efeito de EPDM modificado com grupos mercapto ou tioacetato na cinética de vulcanização de misturas NR/EPDM. Polimeros: Ciência e Tecnologia, 16(4), 299-304. http://dx.doi.org/10.1590/S010414282006000400009 .

Enviado: Nov. 14, 2014

Revisado: Set. 18, 2015 Aceito: Dez. 16, 2015 